\title{
THE PLACE OF PHYSICAL TREATMENT IN POLIOMYELITIS
}

\author{
By John A. Cholmeley, F.R.C.S. \\ Royal National Orthopaedic Hospital, Country Branch, Stanmore, England
}

There has been a great deal of controversial writing and discussion about the type of physical treatment that is best in poliomyelitis and at what stage in the disease this treatment should be started.

Some of the stumbling blocks to a scientific approach to the treatment of this disease are that singularly little is actually known about it, little material has been obtained for pathological examination and this in itself is difficult to carry out owing to the immunity of almost all the usual laboratory animals available for experimental work. Added to this the disease has a sinister reputation with the general public who, at least in times of epidemics, clamour for any line of treatment that is reputed to minimize the crippling effects. Unfortunately in some quarters, the public has been encouraged to expect miraculous cures from treatments which have little scientific foundation.

Before discussing the place of treatment, we must try to obtain a picture of the pathological processes taking place in the certral nervous system both in the acute stage and during the stage of recovery. Sections from the brain and spinal cord from fatal cases show a lymphocytic infiltration of the affected areas, this being most marked around the motor cells of the anterior horns of the spinal cord. In addition to the pericellular and perivascular infiltration, changes occur in the motor cells themselves and it is suggested that the earlier ones are reversible, which would account for the degree of spontaneous recovery from paralysis which is so marked a feature of some cases. An alternative and older conception is that oedema is present during the acute stage of the disease and as this is absorbed, so those nonfunctioning nerve cells not actually destroyed gradually return to normal.

Despite our ignorance of the actual pathology of the disease there is no doubt that clinically some muscles are permanently paralysed and finally degenerate in whole or part depending on the amount of damage to the controlling motor nerve cells, and others suffer from disuse atrophy while the controlling motor cells are temporarily out of action. It should be remembered that degeneration of a muscle is a very slow process.
In addition to the paralysis there is sometimes present in the early stages of the disease a considerable degree of muscle tenderness ; spasm is also described by some observers as occurring in both the paralysed muscles and their nonparalysed antagonists in this stage.

\section{Treatment}

In the acute phase of the disease if there is muscle tenderness or spasm present, both of these are relieved very considerably by the use of heat, hot water bottles, the electric cradle or the application of hot packs as advocated by Sister Kenny. Whether this application of heat can affect the course of the disease is very debatable but certainly it relieves pain and discomfort. In addition to this the patient should be kept recumbent in bed on a soft but firm mattress with a pillow placed under the knees to keep them flexed, a board or foot rest covered by a pillow placed against the feet and a cradle over the patient to avoid pressure by the bed clothes. If an upper limb is affected some degree of abduction of the shoulder should be maintained by placing a firm pillow in the axilla.

It is often found, particularly in children, that simple 'splinting' by pillows is inadequate especially when there is unbalanced paralysis ;. in such a case a plaster gutter or splint is indicated, so made as to give relaxation to the weaker muscles. When the shoulder girdle is affected it is often preferable and more convenient to use a shoulder abduction splint which, in its simplest form, can be made of padded Kramer wire. Whatever splints are used these should be removed for treatment each day and usually for some hours at a time to prevent joint stiffness.

When should active physiotherapy be started ? In the past some surgeons have been so insistent on complete rest that they have postponed any active physical treatment for six to eight weeks from the onset of the disease ; this however may produce stiffness of joints and most certainly will cause disuse atrophy of all the muscles of the limb so immobilized.

Active physical treatment should be started as soon as the temperature is normal and any marked 
muscle tenderness or spasm has disappeared; this is usually not more than a week from the onset of the disease. This active treatment consists essentially of heat, massage, passive movements of all the joints of the affected limbs through their full normal range and re-education exercises. The first two improve the circulation in the affected limbs, passive movements prevent stiffness and active exercises are well recognized to be the best method of re-developing those muscles that are functioning.

In order to carry out exercises the use of slings, pulleys and springs is of great value as gravity can be eliminated where necessary and better control of movement can be obtained. These slings and springs can be suspended from a Balkan beam or similar frame clamped to the bed for stability, or the Guthrie-Smith apparatus can be used. This last permits extremely good control of muscle action to be obtained.

Hydrotherapy or the carrying out of exercises in a warm water pool, first advocated in the treatment of poliomyelitis by Lowman, in 1927, has very considerable advantages as by its use gravity can be eliminated and the patient kept suitably warm ; the pool should be regulated to a temperature of approximately $100^{\circ} \mathrm{F}$.

\section{Electrical Treatment}

Some writers consider that this has no place in the treatment of poliomyelitis; this is almost certainly an overstatement but the indiscriminate use of faradism may definitely do much more harm than good. The use of interrupted galvanism when the intrinsic muscles of the hands are paralysed, does prevent some of the wasting that is very liable to occur and occasionally faradism is valuable when a patient is unable to contract and relax individual muscles successfully by ordinary re-education methods. Finally faradism together with exercises may get just that valuable extra ounce of power out of a permanently weakened muscle.

\section{Duration of Physical Treatment}

There is no doubt that the most rapid and maximum recovery usually takes place during the first six months of treatment; after that time further improvement may occur but at a slower rate. Therefore, if a limb is flail or grossly paralysed at the end of six months' treatment it is unlikely that any worth-while recovery will occur after that period however much physical treatment is given. However, when important muscles such as the erector spinae are seriously affected recumbency will have to be prolonged sometimes up to two years in order to prevent, as far as possible, deformity occurring.

\section{The Iron Lung or Respirator}

This is more of a life-saving apparatus than type of physical treatment but when the inter. costals, diaphragm or abdominal muscles are weat the use of an apparatus such as the Paul-Bragg respirator is a helpful adjunct in treatment, as it helps to rest these muscles if used daily for some hours.

\section{REGISTRAR GENERAL'S STATISTICS}

\section{Reference to the Registrar General's Statistical Review shows that the annual number of} deaths from anterior poliomyelitis in England and Wales since $192 \mathrm{I}$ has averaged 103, the extremes being 61 in 1943 and 176 in 1926. The latter figure was closely approached in 1938 when there were 174 deaths representing a case mortality of 16 per cent. The notification rate was 4 per 100,000 population.

During the epidemic year 1947, 7I5 deaths were recorded from poliomyelitis, the case mortality being 9 per cent. and the notification rate 18 per 100,000. The incidence of the disease was therefore four and a half times greater than previously recorded, although the case mortality was not so high. 